\title{
Dificuldades no Desenvolvimento da Lectoescrita: O Papel das Habilidades Metalinguísticas
}

\author{
Sandra Regina Kirchner Guimarães \\ Universidade Federal do Paraná
}

\begin{abstract}
RESUMO - Este estudo investigou a relação entre habilidades metalingüísticas (consciência fonológica e sintática) e desempenho na leitura e na escrita (ortografia) de palavras isoladas. Foram formados três grupos de sujeitos: 20 crianças com dificuldades em leitura e escrita, cursando $3^{\mathrm{a}}$ e $4^{\mathrm{a}}$ séries (grupo 1); 20 crianças da $1^{\mathrm{a}}$ série, com o mesmo nível de leitura e escrita dos sujeitos do grupo 1 (grupo 2) e 20 crianças da $3^{\mathrm{a}}$ e $4^{\mathrm{a}}$ séries, com a mesma idade cronológica dos sujeitos do grupo 1 (grupo 3). Esperava-se que o grupo 1 apresentasse escores inferiores nas habilidades metalinguí́sticas, quando comparado aos outros grupos. A hipótese foi confirmada apenas para os escores em consciência fonológica. Em relação à consciência sintática, não se observou diferença significativa entre os grupos 1 e 2, os quais tiveram um desempenho inferior ao do grupo 3. Os resultados mostraram que as dificuldades em leitura e escrita estão relacionadas predominantemente com problemas de natureza fonológica.
\end{abstract}

Palavras-chave: desenvolvimento da linguagem; habilidades metalingüísticas; consciência fonológica; consciência sintática; dificuldades de lecto-escrita.

\section{Difficulties in Literacy Development: The Role of Metalinguistics Skills}

\begin{abstract}
This study investigated the relationship between metalinguistic skills (phonological and syntactical awareness) and the ability at reading and spelling. The study involved three groups of subjects: 20 third- and fourth-grade children with reading and spelling problems (group 1); 20 first-grade children with the same reading and spelling skill level of those in group 1 (group 2); 20 third- and fourth-grade children the same age as those in group 1 (group 3). Group 1 was expected to show lower scores on metalinguistic skills, when compared with the other groups. The hypothesis was confirmed only in what regards to phonological awareness scores. Regarding to syntactical awareness, no significant difference was observed between groups 1 and 2, whose scores were lower than those in group 3 . The results of this study have shown that reading and spelling problems are predominantly linked to phonological mediation problems.
\end{abstract}

Key words: literacy development; metalinguistic skills; phonological awareness, syntactic awareness; reading and spelling problems.

No curso da evolução das concepções relativas às dificuldades de aprendizagem em leitura e escrita, identificam-se diferentes hipóteses explicativas. Bryant e Bradley (1985/1987) relatam que muitos déficits já foram sugeridos, mas com o passar dos anos, essas sugestões têm mudado. Inicialmente, pensava-se que um "leitor fraco" ou "mau leitor" não visse ou escutasse de forma apropriada e as dificuldades de aprendizagem da leitura e da escrita costumavam ser atribuídas às deficiências de processamento visual. A partir dos anos 70, diversos estudos mostraram que as habilidades metalingüísticas parecem primordiais no acesso à escrita e revelam-se associadas a maior ou menor eficácia na aprendizagem da leitura e da escrita. Com efeito, o domínio pleno da leitura e da escrita exige conhecimentos claros de diversos aspectos da linguagem e supõe uma tomada de consciência das características formais da linguagem (p. ex.: estrutura fonêmica, estrutura sintática).

1 Trabalho adaptado de parte da Tese de Doutorado apresentada ao Instituto de Psicologia da Universidade de São Paulo, sob a orientação da Professora Dra . Eda Marconi Custódio.

2 Endereço: Departamento de Teoria e Fundamentos da Educação, Setor de Educação, Universidade Federal do Paraná, Rua General Carneiro, 460 - $4^{\circ}$ andar, 80060-100, Curitiba PR. E-mail: sonnyg@uol.com.br
O sistema alfabético de escrita associa um componente auditivo fonêmico a um componente visual gráfico (correspondência grafofonêmica). De acordo com Byrne e Fielding-Barnsley (1989), para a compreensão do princípio alfabético são necessários três fatores: 1) a consciência de que é possível segmentar a língua falada em unidades distintas; 2) a consciência de que essas mesmas unidades repetem-se em diferentes palavras faladas; 3 ) o conhecimento das regras de correspondência entre grafemas e fonemas. Destaca-se que os dois primeiros fatores são aspectos da consciência fonológica ${ }^{3}$, e isto a coloca como indispensável no desenvolvimento da leitura e da escrita.

Esse papel central da consciência fonológica sobre a aprendizagem da leitura e da escrita é atestado pelos resultados de numerosos trabalhos de pesquisa submetendo indivíduos (de diversas idades cronológicas e diferentes níveis léxicos) a várias provas de análises fonológicas. Esses

3 Neste artigo, seguindo a tendência de outros pesquisadores (Capovilla, 1999; Share, 1995), será utilizado o termo consciência fonológica para designar uma consciência geral dos segmentos que compõem a fala (rimas, aliterações, sílabas e fonemas) e o termo consciência fonêmica para a consciência específica de fonemas. 
estudos têm demonstrado que o desempenho das crianças pré-escolares, em determinadas tarefas de consciência fonológica, relaciona-se com o sucesso na aquisição da leitura e da escrita (Juel, Griffith \& Gough, 1986; Stanovich, Cunningham \& Cramer, 1984; Treiman \& Baron, 1983; Yopp, 1988). Há também evidência de que o treinamento da consciência fonológica pode exercer uma influência benéfica na aprendizagem da leitura e da escrita (Byrne \& Fielding-Barnsley, 1993; Lundberg, Frost \& Petersen, 1988; Williams, 1980), sobretudo quando associado ao treinamento do reconhecimento das correspondências entre as letras e os sons (Byrne, 1996; Hohn \& Ehri, 1983).

$\mathrm{Na}$ realidade, como bem afirmam Bryant e Goswami (1987), a descoberta de uma relação entre a consciência fonológica das crianças e seus progressos na aquisição da leitura e da escrita é um dos grandes sucessos da psicologia moderna. Contudo, diversas posições sobre a relação entre consciência fonológica e desenvolvimento da leitura e da escrita vêm sendo apresentadas ao longo das últimas décadas. Uma delas, refletida nos estudos de Bradley e Bryant (1983) e sustentada, mais tarde, por Goswami e Bryant (1997), considera que a consciência fonológica (enquanto habilidade para detectar aliteração e rima) é preditora do progresso na aquisição da leitura e da escrita. A explicação sugerida para este progresso diz respeito ao uso de analogias, ou seja, a habilidade de perceber que duas palavras rimam pode tornar a criança sensível às semelhanças ortográficas no final destas palavras e, desse modo, possibilitar que estabeleça conexões entre padrões ortográficos e sons no final das palavras.

Uma outra posição (Ehri \& Robbins, 1992) destaca que a capacidade de fazer analogias no final de palavras pressupõe capacidade de decodifação letra-som. Estes autores salientam que a habilidade de detectar fonemas em uma palavra é influenciada pelo conhecimento ortográfico.

Entretanto, uma terceira posição salienta uma causação recíproca entre consciência fonológica e aquisição da leitura e da escrita. Desse modo, os estágios iniciais da consciência fonológica contribuem para o desenvolvimento dos estágios iniciais do processo de leitura e estes, por sua vez, contribuem para o desenvolvimento de habilidades de consciência fonológica mais complexas. Portanto, enquanto a consciência de alguns segmentos sonoros (supra-fonêmicos) parece desenvolver-se espontaneamente, a consciência fonêmica parece exigir experiências específicas em atividades que possibilitem a identificação da correspondência entre os elementos fonêmicos da fala e os elementos grafêmicos da escrita. (Alégria, Leybaert \& Mousty, 1994/1997; Bertelson, Morais, Alegria \& Content, 1985; Demont, 1994/1997; Perfetti, Beck, Bell \& Hughes, 1987).

No entanto, para fundamentar de forma mais apropriada este trabalho é imprescindível uma revisão de estudos que investigam o papel da consciência fonológica sobre a aprendizagem da leitura e da escrita em Português, pois se deve considerar a peculiaridade de cada língua no que diz respeito ao grau de equivalência grafo-fonêmica. Na verdade, os estudos que abordam a relação entre a consciência fonológica e o desenvolvimento da leitura e da escrita são abundantes na literatura internacional; contudo, os primeiros trabalhos de Língua Portuguesa, datam da década de 80 (por exemplo, Carraher \& Rego, 1981).
Destaca-se que uma das investigações mais expressivas abordando a relação entre diferentes níveis da consciência fonológica (identificação de rimas, sílabas e fonemas) e a aquisição da leitura e da escrita foi realizada por Cardoso-Martins (1995). De acordo com os resultados dessa investigação, a habilidade das crianças para detectar rimas no início da instrução formal em leitura (mais ou menos aos seis anos de idade) foi preditiva da sua capacidade de leitura quatro meses mais tarde, mas não serviu como preditor da capacidade demonstrada no final do ano escolar. Entretanto, a habilidade para detectar rimas não foi preditiva da capacidade ortográfica das crianças em nenhum dos momentos da pesquisa. ${ }^{4}$ Além disso, a habilidade na tarefa de identificação da sílaba inicial serviu como preditor da capacidade de leitura tanto aos quatro quanto aos oito meses após o início do ano letivo, embora não tenha servido para prever a capacidade ortográfica. Por outro lado, a referida pesquisadora verificou que a habilidade de identificação de fonema inicial revelou-se capaz de prever significativamente a capacidade de leitura e de escrita nos dois momentos da pesquisa (quatro e oito meses após o início do ano letivo). Em suma, os resultados de Cardoso-Martins (1995) sugerem que a consciência fonêmica representa o nível de consciência fonológica que tem o papel mais importante na aquisição da leitura e da escrita em Português.

Estudos posteriores, realizados com crianças brasileiras, corroboraram os resultados do estudo de Cardoso-Martins (1995). Assim, Maluf e Barrera (1997) encontraram uma alta correlação entre os níveis de consciência fonológica e de aquisição da linguagem escrita e, além disso, Morais (1997) constatou que os leitores não-proficientes, apesar de perceberem a palavra enquanto seqüência lingüística, obtiveram piores resultados nas provas de consciência fonológica, principalmente em relação à detecção de fonemas finais. Ademais, o estudo de Capovilla (1999) demonstrou que o fornecimento de instruções fônicas explícitas às crianças facilita a aquisição de leitura e escrita.

Por outro lado, alguns autores têm demonstrado que a consciência sintática contribui igualmente para a aquisição da leitura e da escrita. Um dos primeiros estudos que forneceu sustentação a esta idéia foi realizado por Guthrie (1973). Ele comparou um grupo de crianças de 10 anos de idade, com dificuldades de leitura, com um grupo de crianças de sete anos de idade; ambos os grupos apresentavam nível de leitura equivalente a sete anos de idade. $\mathrm{O}$ referido pesquisador constatou que as crianças mais novas, que apresentavam nível de leitura adequado para a sua idade, tiveram um desempenho significativamente melhor que as crianças mais velhas, em uma tarefa de leitura, na qual as crianças eram solicitadas

4 Cardoso-Martins (1995) explicou por que a habilidade de detectar rima é menos importante em português do que em inglês. Em inglês, a maioria das palavras que as crianças encontram nos livros inicias de leitura são monossilábicas; logo, ao detectarem a rima estarão identificando que duas palavras têm um segmento em comum, isto é, a "rime". Por outro lado, em português há uma preponderância de palavras multissilábicas paroxítonas e, na maior parte dessas palavras as rimas não correspondem a segmentos intra-silábicos, mas sim a segmentos maiores do que as sílabas. Por exemplo, no par de palavras chupeta e roleta a rima corresponde ao segmento eta. Assim, a habilidade de discriminar rimas não precisa envolver a habilidade de discriminar pequenos segmentos intra-silábicos (ataque/rima ou fonema). 
a escolher, a cada cinco palavras (aproximadamente), qual dentre três palavras alternativas seria a palavra correta a inserir naquele ponto no texto. Os dados obtidos nesse estudo levaram Guthrie (1973) a concluir que as crianças com dificuldades de leitura têm menor habilidade que as outras crianças para utilizar pistas gramaticais na leitura.

Um outro estudo, realizado por Tunmer, Nesdale e Wright (1987) comparou crianças mais jovens (bons leitores), do mesmo nível de leitura de crianças mais velhas (maus leitores), em diversas tarefas, sendo duas delas de consciência sintática (completar oralmente as palavras ausentes nas sentenças e corrigir sentenças gramaticalmente incorretas, porque as palavras estavam na ordem errada). Os resultados indicaram que as crianças mais jovens, os bons leitores, saíram-se melhor nas tarefas de consciência sintática do que as crianças mais velhas, os maus leitores. Para Tunmer e cols., esse resultado constitui evidência de que o atraso no desenvolvimento da consciência sintática pode retardar o desenvolvimento da capacidade de leitura, sugerindo que a consciência sintática pode estar relacionada com as dificuldades (diferenças) na aprendizagem da leitura. Nesta perspectiva, eles formularam a hipótese de que a aprendizagem inicial da leitura era influenciada tanto pela consciência fonológica quanto pela consciência sintática. Ou seja, a consciência fonológica influenciaria diretamente a aquisição das correspondências fonema-grafema que está ligada ao processo de decodificação. Entretanto, a consciência sintática possibilita que as crianças focalizem as palavras enquanto categorias gramaticais e sua posição na frase, o que, por sua vez, aumenta sua capacidade de identificação e produção de palavras escritas. Por exemplo, imaginando-se uma frase no pretérito perfeito, terceira pessoa do singular: muitos sujeitos dizem /falô/ para "falou", /dançô/ para "dançou" etc., não pronunciando o U final. Assim, uma criança na fase alfabética que tente simplesmente representar os sons das palavras tem, portanto, uma alta probabilidade de omitir o U final. Por outro lado, se ela tiver capacidade para refletir e manipular mentalmente a estrutura gramatical das sentenças, poderá utilizar essa capacidade para solucionar suas possíveis dificuldades de leitura e escrita.

Para testar esta hipótese, Tunmer, Herriman e Nesdale (1988) conduziram um estudo com 100 crianças australianas, nas quais foram administradas uma tarefa de consciência sintática (corrigir sentenças incorretas) e uma tarefa de consciência fonológica (contar os fonemas de palavras sem sentido). Por meio desse estudo, os pesquisadores constataram uma relação preditiva entre esses dois aspectos da consciência metalingüística (consciência sintática e consciência fonológica) e o desenvolvimento da capacidade da criança na decodificação e compreensão da leitura.

Mais recentemente, Gottardo, Stanovich e Siegel (1996) realizaram um estudo investigando a relação entre a sensibilidade fonológica, o processamento sintático ${ }^{5}$ e a memória verbal

5 Gottardo, Stanovich e Siegel (1996) defendem que em lugar do termo "consciência fonológica" se utilize "sensibilidade fonológica" para designar os diferentes níveis de habilidade fonológica, os quais podem envolver unidades silábicas, subsilábicas ou fonêmicas. Além disso, é importante destacar que os mesmos autores utilizam o termo "habilidade de processamento sintático" para se referirem à "consciência sintática" (p.565). de curto prazo com o desempenho em leitura de crianças da terceira série (falantes do inglês). De acordo com os referidos pesquisadores, os dados levantados nesse estudo indicam que a sensibilidade fonológica, isoladamente, era um forte preditor do desempenho em leitura, enquanto que a habilidade de processamento sintático não era preditiva da capacidade de reconhecimento de palavras, leitura de palavras inventadas ou compreensão da leitura. De acordo com Gottardo e cols., esses resultados sustentam a hipótese da limitação do processamento fonológico de Shankweiler, Crain, Brady e Macaruso (1992), segundo a qual os problemas no processamento fonológico tornam-se um "gargalo" que impede a operação de outros processos cognitivos de nível mais elevado. Desse modo, as correlações entre as dificuldades na leitura e a consciência sintática deficiente surgem como um epifenômeno das deficiências no processamento fonológico.

Em estudo posterior, Bryant, Nunes e Bindman (1997) investigaram a relação entre a consciência sintática e o desempenho em escrita (ortografia), levantando três diferentes hipóteses explicativas:

$1^{\mathrm{a}}$ os sujeitos maus leitores/escritores apresentam adequado desenvolvimento da consciência sintática, porém, fraco desempenho em ortografia, porque a aprendizagem inicial da linguagem escrita (leitura e escrita) foi dificultada pela sua deficiência em consciência fonológica;

$2^{\mathrm{a}}$ os sujeitos maus leitores/escritores apresentam pouca sensibilidade para distinções lingüísticas (tanto sintáticas como fonológicas) e seu fraco desempenho em ortografia é decorrente de uma deficiência específica em consciência sintática;

$3^{\mathrm{a}}$ existe uma causação recíproca entre consciência sintática e desenvolvimento da escrita. Assim, a consciência sintática pode se desenvolver a partir das experiências dos sujeitos com a linguagem escrita, da mesma forma que a consciência sintática constitui a base para a utilização de novas estratégias de leitura e de escrita.

De acordo com os resultados de Bryant e cols. a aprendizagem da linguagem escrita proporciona uma contribuição significante para o desenvolvimento da consciência sintática, uma vez que ela se mostrou mais desenvolvida nos maus leitores/escritores do que nos sujeitos emparelhados a eles pelo nível de leitura e de escrita. Além disso, esses autores não encontraram evidências de que os maus leitores/escritores tivessem uma deficiência específica em consciência sintática.

Em relação aos estudos em Português, verifica-se que o número de pesquisas considerando a relação entre consciência sintática e aprendizagem da leitura e da escrita é bastante reduzido e, ao contrário das pesquisas que focalizam a consciência fonológica, não existe concordância entre os resultados obtidos. Por exemplo, um primeiro estudo realizado por Rego (1993) envolvendo 32 crianças brasileiras, que freqüentavam uma escola de orientação construtivista, verificou que a consciência sintática constitui-se um bom preditor do progresso das crianças tanto na decodificação quanto na compreensão da leitura. Entretanto, um outro estudo de Rego (1995), envolvendo 50 crianças brasileiras, alfabetizadas por meio de um método tradicional com ênfase exclusiva no ensino de padrões silábicos, apresentou resultados diferentes, ou seja, não foi encontrada uma conexão entre consciência sintática e progresso inicial em decodificação. 
Barrera (2000), que efetuou um estudo com 65 crianças da $1^{\text {a }}$ série, também falantes do Português, testou a hipótese de que as habilidades metalingüísticas (consciência fonológica, lexical e sintática) desempenham um papel facilitador na aquisição da linguagem escrita e que a utilização de variedades lingüísticas não-padrão dificulta essa aquisição. Os resultados desta investigação mostraram correlações positivas entre os níveis de consciência fonológica e sintática no início do ano letivo e o desempenho em leitura e escrita no final do ano. Entretanto, a consciência lexical apresentou uma correlação significativa apenas com o nível de leitura verificado no final do ano. Por outro lado, os níveis de variação lingüística, embora tenham mostrado uma tendência em se relacionar negativamente com os desempenhos em leitura e escrita, apresentaram uma correlação significativa apenas com o resultado final em leitura. Desse modo, a referida autora concluiu que, de fato, os alunos que iniciaram o processo de alfabetização com níveis mais avançados de habilidades metalingüísticas e níveis mais baixos de variação lingüística apresentaram melhor desempenho em leitura e escrita no final do ano letivo.

De qualquer maneira, embora os resultados de Barrera (2000) corroborem os resultados encontrados em um dos estudos de Rego (1993), o fato de haver resultados contraditórios entre os estudos aponta para a necessidade de novas e mais profundas investigações com sujeitos falantes do Português. Evidentemente, nesses estudos há que se considerar a hipótese de Rego (1995) de que a influência da consciência sintática sobre o desempenho inicial em leitura depende do método instrucional a que foi exposto o leitor. Contudo, enquanto não houver um acordo quanto à importância da consciência sintática para o desenvolvimento da lectoescrita em Português, permanece a necessidade de novos estudos para investigar como a capacidade das crianças para fazer julgamentos a respeito das sentenças se relaciona com o processo de aprendizagem da leitura e da escrita.

Em suma, o contexto no qual este estudo se insere apresenta consenso a respeito da importância da consciência fonológica para o desenvolvimento da lectoescrita, enquanto que a influência da consciência sintática sobre esse desenvolvimento permanece ainda um foco de debate. Assim, existe todo um corpo teórico, principalmente na literatura internacional, demonstrando a existência de uma importante relação entre consciência sintática e aquisição da leitura e da escrita. Entretanto, persiste a hipótese de que a relação entre consciência sintática e desenvolvimento da lectoescrita depende do método de alfabetização utilizado.

Enfim, considerando que a aquisição da linguagem escrita é um processo complexo que requer múltiplas habilidades cognitivas, entre elas as habilidades metalingüísticas, este estudo pretende contribuir para avançar o conhecimento acerca do tema estudando uma população específica, ou seja, sujeitos que apresentam dificuldades de aprendizagem da leitura e da escrita em Português. Portanto, a condução deste estudo teve como objetivo central avaliar os níveis de consciência fonológica e consciência sintática dos alunos sujeitos da pesquisa, analisando a relação entre essas habilidades metalingüísticas e as diferenças de desempenho na leitura e na escrita de palavras isoladas.

Ademais, é importante salientar que, como o propósito deste trabalho é analisar as dificuldades do desenvolvimen- to inicial da leitura e da escrita, acredita-se que os sujeitos estudados são ainda muito dependentes de estratégias ligadas diretamente ao reconhecimento e escrita de palavras isoladas. Assim, este estudo ocupa-se mais diretamente das dificuldades envolvidas na decodificação e codificação de palavras. Logo, no que se refere à escrita, este trabalho trata exclusivamente da ortografia, que, reconhecidamente, é uma parte pequena (mas importante) do ato de escrever. Destaca-se, por conseguinte, que não é objeto deste estudo a compreensão/produção de textos.

A princípio, as hipóteses de trabalho propostas pela pesquisadora foram as seguintes:

- Em geral, os sujeitos que apresentarem os escores mais elevados nas tarefas que avaliam as habilidades metalingüísticas (consciência fonológica e consciência sintática) mostrarão também os melhores desempenhos nas tarefas de leitura e de escrita.

- O grupo de sujeitos com dificuldades de aprendizagem da leitura e da escrita apresentará escores inferiores nas tarefas que avaliam a consciência fonológica e a consciência sintática ${ }^{6}$, quando comparados com os demais sujeitos da pesquisa, tanto com aqueles de sua idade cronológica, como com aqueles de seu nível de leitura e escrita.

\section{Método}

\section{Sujeitos}

O universo da pesquisa era formado por alunos da 1. $3^{a}$ e $4^{a}$ séries do Ensino Fundamental de Escolas da Rede Municipal de Ensino de Curitiba, que possuem salas de recursos. $^{7}$

Do referido universo (que abrange 20 escolas, agrupadas em sete núcleos), foram escolhidas aleatoriamente seis escolas e após obter o consentimento dos responsáveis das escolas para a realização da investigação científica, a pesquisadora aplicou o Teste de Desempenho Escolar -TDE (Stein, 1994) nos alunos das salas de recursos, indicados pelos professores como tendo fraco desempenho em leitura e escrita. Com base nos resultados do Teste de Desempenho Escolar-TDE, o presente estudo ficou restrito a três escolas, onde foram identificados 20 alunos com dificuldades de aprendizagem da leitura e da escrita, os quais compuseram o grupo 1. Além desse grupo, foram selecionados entre os alunos dessas três escolas outros dois grupos, formados por sujeitos emparelhados aos do grupo 1, a saber:

6 Acompanhando a segunda hipótese explicativa da relação entre consciência sintática e desempenho em ortografia de Bryant, Nunes e Bindman (1997), espera-se que os sujeitos com dificuldades de aprendizagem da leitura e da escrita apresentem um nível de consciência sintática inferior ao dos sujeitos emparelhados a eles pelo nível de leitura e de escrita, os quais possuem um nível de consciência sintática adequado para sua idade.

7 Em relação às salas de recursos, é importante ressaltar que elas "foram implantadas na Rede Municipal de Ensino a partir da necessidade de se oferecer atendimento aos alunos que apresentavam Dificuldades de Aprendizagem e Deficiência Auditiva, cujas características não recomendavam atendimento em Classe Especial." (Curitiba, 1992, p. 50). De acordo com a necessidade de cada aluno, ele participa de atendimento nesta modalidade de ensino especial de uma a duas vezes por semana, sempre no período oposto ao da classe regular. 
Grupo 1 - composto por 20 alunos (14 da $4^{\mathrm{a}}$ série e 6 da $3^{\mathrm{a}}$ série) com idade variando de 10 anos a 13 anos e 6 meses (média 11 anos e 6 meses), que freqüentavam salas de recursos e apresentavam dificuldades na aprendizagem da leitura e da escrita. Estes alunos foram selecionados pelos escores obtidos no Teste de Desempenho Escolar - TDE, ou seja, aqueles que obtiveram em leitura e escrita escores muito inferiores ao esperado para a sua série, embora tivessem obtido em aritmética um escore correspondente à série que freqüentavam.

Grupo 2 - composto por 20 alunos da $1 .{ }^{a}$ série com idade variando de 6 anos e 3 meses a 7 anos e 10 meses (média 7 anos e 1 mês), emparelhados com os sujeitos do Grupo 1 pelo nível de leitura e escrita ${ }^{8}$. Estes foram selecionados de acordo com os resultados do teste TDE, ou seja, obtiveram escores em leitura e escrita adequados à sua série. Portanto, eram alunos sem dificuldades de aprendizagem e com idade cronológica inferior a dos alunos do grupo 1 .

Grupo 3 - composto por 20 alunos ( 14 da $4^{a}$ série e 6 da $3^{\mathrm{a}}$ série), provenientes das mesmas turmas (salas regulares) que os alunos do Grupo 1 e emparelhados com eles de acordo com a idade cronológica, por conseguinte, apresentavam idade variando de 10 anos a 13 anos e 1 mês (média 11 anos e 1 mês). Para a seleção desses sujeitos, além do critério de idade, foi utilizado também o teste TDE, para verificar se eles obtinham escores em leitura e escrita adequados às suas séries. Logo, eram alunos sem dificuldades na aprendizagem da leitura e da escrita com a mesma idade cronológica dos sujeitos do grupo 1.

De acordo com os dados fornecidos pelas equipes pedagógico-administrativas das escolas, seus alunos são oriundos de famílias que apresentam uma renda familiar de dois a cinco salários mínimos. Além disso, a escolaridade da maioria dos pais dos alunos está em nível de $1^{\circ}$ grau. A partir desses dados considerou-se que não havia variação sócio-econômica significativa entre os sujeitos pesquisados.

\section{Provas utilizadas}

O presente estudo foi baseado em quatro tipos de provas experimentais:

\section{Medidas de controle ${ }^{9}$}

Foram usadas as mesmas medidas de controle utilizadas no estudo de Rego (1995), ou seja, uma medida de inteligência que foi realizada por meio do teste das Matrizes Progressivas Coloridas de J. C. Raven e uma tarefa de me-

8 Delineamentos de pesquisa com grupo de controle emparelhado pela idade de leitura têm sido usados por diversos pesquisadores (Bradley \& Bryant, 1978; Bryant \& Bradley, 1985/1987; Bryant, Nunes \& Bindman, 1997; Kajihara, 1997; Tunmer, Nesdale \& Wright, 1987). Justifica-se a utilização desse grupo de controle numa intervenção quando as tarefas empregadas não são exclusivamente de leitura e escrita, mas podem ter uma relação causal com as mesmas.

9 Embora no delineamento do presente estudo não tenha sido previsto o controle da variação lingüística, ou seja, não foi avaliada a distância entre a fala da criança e a norma padrão utilizada na escola, destaca-se que esta e uma variável que pode estar significativamente relacionada com o desenvolvimento da leitura e da escrita (cf. Barrera, 2002). Registra-se, portanto, a necessidade de incluir esta variável quando da realização de futuros estudos. mória verbal. Entretanto, para os sujeitos com mais de 11 anos e 8 meses foi utilizado o teste de Matrizes Progressivas - Escala Geral.

O objetivo de efetuar uma medida de controle da inteligência neste estudo (no qual se busca identificar os fatores cognitivos relacionados às dificuldades de aprendizagem da leitura e da escrita), deve-se ao fato de que a inteligência é uma variável freqüentemente associada ao sucesso escolar.

Do mesmo modo, considera-se fundamental uma tarefa de controle da memória verbal, uma vez que, tanto as tarefas de consciência fonológica e de consciência sintática, como as tarefas de leitura e de escrita, envolvem a retenção de informações verbais na memória a curto prazo. Portanto, o objetivo da tarefa de memória verbal é controlar os eventuais efeitos desse tipo de memória.

Na tarefa de memória verbal, foi solicitado à criança que repetisse literalmente as 14 sentenças (duas de treinamento e doze de exame) ditas pela pesquisadora. Estas

sentenças apresentavam tamanho e nível de complexidade crescente. A primeira sentença que a criança deveria repetir era "Ontem choveu muito" e a última era "Carlos bebeu o leite porque ele gosta de brincar com Luiz quando está em casa".

Antes de iniciar a tarefa propriamente dita, a pesquisadora praticava com a criança as duas sentenças de treino. O escore de acerto na tarefa podia variar de 0 a 12 , pois as crianças recebiam um ponto para cada uma das 12 sentenças que conseguissem repetir corretamente.

\section{Tarefas de leitura e escrita de palavras reais e de palavras inventadas}

Esta prova consiste em duas tarefas: uma envolvendo a leitura, pelos sujeitos, de palavras reais e palavras inventadas, e a outra, envolvendo a escrita das mesmas palavras, que é realizada a partir de ditado.

O material que foi empregado nesta prova é composto por dois conjuntos (A e B), cada um contendo 18 palavras reais e 9 palavras inventadas, e se constitui numa versão modificada das listas experimentais de palavras reais e palavras inventadas utilizadas por Pinheiro (1994) em seu estudo. As palavras inventadas foram construídas com as mesmas estruturas ortográficas e comprimentos (4-7 letras) das palavras reais. As palavras inventadas do conjunto $\mathrm{A}$ foram criadas a partir de alterações em uma ou duas letras de palavras reais do conjunto B e vice-versa.

As palavras que compuseram o conjunto A foram as seguintes:

- palavras reais: festa, papai, chuva, vila, cabras, batalha, casa, galinha, pássaro, nora, empada, usam, hoje, feliz, amanhã, boxe, açude, hino.

- palavras inventadas: dalé, dolhas, calafra, sissi, dampém, mepação, inça, danãe, nezema.

As palavras que compuseram o conjunto B foram as seguintes:

- palavras reais: café, folhas, palavra, jipe, pesca, moeda, disse, também, redação, quietos, florido, marreca, onça, mamãe, dezena, luzes, xerife, descida.

- palavras inventadas: vesta, bavai, chuda, dasa, gavinha ${ }^{10}$, jássaco, hove, saliz, atanhã. 
Para a tarefa de leitura, as palavras dos dois conjuntos, que contém cada um 18 palavras reais e 9 inventadas, foram apresentadas em cartões individuais tamanho $7 \times 4,5 \mathrm{~cm}$, sendo as letras impressas em fonte Arial (18 pontos e caixa baixa).

A tarefa de escrita foi realizada a partir de ditado dos mesmos conjuntos de palavras reais e inventadas, mas em sessões alternadas: na sessão em que foi lida a lista A, foram ditadas as palavras da lista B e vice-versa.

$\mathrm{O}$ escore das crianças nas tarefas reflete o número de palavras lidas ou escritas corretamente.

\section{Tarefas de avaliação da consciência fonológica:}

\section{A) Tarefa de Segmentação Fonológica}

Seguindo o procedimento adotado por Vernon (1998) em uma pesquisa com crianças falantes do espanhol, esta tarefa requeria que a criança segmentasse (no menor número de segmentos que ela conseguisse) 12 palavras, sendo duas de treinamento e 10 de exame. Entre as palavras que deveriam ser segmentadas, quatro eram monossílabas (giz, sol, boi, flor) e oito eram dissílabas (pato, focas, sapo, cobra, carro, prato, peixe, barco).

Antes do início da tarefa, a instrução recebida pela criança era a seguinte:

Eu vou dar para você uma série de cartões com algumas figuras. Você não deverá dizer estas palavras inteiras, mas em pedaços - no maior número de pedaços que você conseguir. Por exemplo, se eu lhe mostrar esta figura (pato) você não deve dizer o seu nome inteiro, mas em pedaços..

Então ..... em que pedaços nós podemos dividir esta palavra?

Se a criança não soubesse responder, era ensinada uma segmentação silábica (pa-to). Se a criança já tivesse feito uma segmentação silábica, ou depois de ser ensinada a fazê-lo, a pesquisadora a incentivava para que fizesse uma segmentação em pedaços ainda menores, fazendo com que a criança compreendesse ou produzisse segmentações cada vez mais refinadas. Para verificar o desempenho dos sujeitos nesta tarefa, foi considerado o percentual de palavras corretamente segmentadas em fonemas, dentre os 10 itens que foram apresentados.

\section{B) Tarefa de Categorização Fonológica}

Nesta tarefa foi solicitado às crianças que identificassem, entre quatro palavras, qual a que compartilhava o segmento inicial ou final com a palavra-estímulo apresentada pela pesquisadora. Foram examinadas duas condições, ou seja, categorização de segmentos iniciais e categorização de segmentos finais, usando-se como referência o estudo de Cordeiro (1999), do qual foram retiradas as palavras utilizadas nesta tarefa.

10 A palavra gavinha, que designa um órgão de fixação das plantas trepadeiras, foi mantida como palavra inventada, porque se acredita que os sujeitos da pesquisa não conheciam esta palavra e, principalmente, para repetir fielmente as palavras do estudo de Pinheiro (1994).
Em relação à categorização dos segmentos iniciais foram examinadas três subcondições:

- emparelhamento de palavras com base na sílaba inicial (p. ex.: Para a realização desta tarefa (p. ex.: palavra-estímulo - trigo, itens para identificação da palavra semelhante - flecha, carta, trilhos, bruxa);

- emparelhamento de palavras com base no grupo consonantal inicial (p. ex.: palavra-estímulo - brinco, itens para identificação da palavra semelhante - braço, bala, grade, galo);

- emparelhamento de palavras com base no fonema inicial (p. ex.: palavra-estímulo - brinco, itens para identificação da palavra semelhante - tromba, blusa, fruta, globo).

Em relação à categorização dos segmentos finais foram examinadas duas subcondições:

- emparelhamento de palavras com base na sílaba final (p. ex.: palavra-estímulo - jardim, itens para identificação da palavra semelhante - pudim, jornal, colher, pintor);

- emparelhamento de palavras com base na vogal final (p. ex.: palavra-estímulo - tigre, itens para identificação da palavra semelhante - pista, pente, patim e pinto).

Para a realização desta tarefa, tanto as palavras-estímulo como as palavras-contraste foram acompanhadas de figuras dos objetos mencionados, para evitar a interferência da memória na decisão das crianças, ou seja, escolher apenas as palavras que tiverem lembrado. Como medida do desempenho das crianças, considerou-se o percentual relativo ao número total de pares de palavras semelhantes identificado.

\section{C) Tarefa de Subtração de fonema inicial}

O objetivo dessa tarefa era verificar a habilidade das crianças na subtração de fonemas. Para tanto, foi solicitado que as crianças repetissem as palavras apresentadas sem o fonema inicial. Esta tarefa envolveu 12 itens ( 2 para treino e 10 para exame), que foram apresentados para as crianças de forma oral. As palavras que compuseram a tarefa são as seguintes: casa, luva, anão, povo, laço, bela, mato, canta, sobra, filha, cidade, cantiga.

Como desempenho dos sujeitos foi considerado o percentual de acertos na subtração do fonema inicial das 10 palavras de exame.

\section{Tarefas de avaliação da consciência sintática:}

\section{A) Tarefa de complementação}

Nesta tarefa, foi pedido para as crianças que tentassem adivinhar as 15 palavras omitidas de um texto que era lido para ela, ou seja, de um texto do qual elas não tinham acesso visual. As palavras omitidas pertencem a classes diferentes (substantivo, adjetivo, numeral, pronome, verbo). Antes do início da tarefa propriamente dita, a criança fazia um treino, ou seja, ela ouvia uma frase e apresentava as duas palavras que haviam sido omitidas (ver Anexo A).

Essa tarefa foi elaborada usando como referência a tarefa de completar palavras omitidas do texto utilizado por Tunmer, Nesdale e Wright (1987) em seu estudo. Entretanto, ressalta-se que ela pode ser considerada como uma tarefa sintático-semântica, pois o sujeito pode utilizar tanto pistas 
sintáticas como semânticas para "adivinhar" as palavras omitidas do texto. Assim, para correção dos diversos itens dessa tarefa foi utilizado o mesmo critério adotado por Tunmer e cols. (1987, p.30), ou seja, as respostas das crianças foram consideradas corretas quando as palavras indicadas eram apropriadas para o contexto da sentença. Como o número de acertos podia variar de zero a 15, o escore obtido pelos sujeitos foi transformado em porcentagem.

Ademais, verificou-se durante a aplicação da tarefa que em algumas situações, especialmente na passagem do texto que diz no "uhm" seguinte, as crianças podiam adivinhar as palavras omitidas utilizando-se da memória verbal, pois esse tipo de frase é comum no contexto de uma narrativa. Reconhece-se contudo que essas situações, embora possam ter causado efeito sobre os resultados dessa tarefa, não foram totalmente identificadas e nem controladas.

\section{B) Tarefa de correção da ordem dos componentes das frases}

Nesta tarefa, foi apresentada para as crianças uma série de frases em que as palavras estavam gramaticalmente desordenadas. Assim, a tarefa consistia em que elas repetissem as frases, com as palavras na ordem correta. Todas as frases que as crianças deveriam corrigir continham agramaticalidades como, por exemplo, "Está o quente leite", "Eu discos meus vendi", "Está abacate maduro o". Esta tarefa constitui-se de uma modificação da tarefa utilizada por Rego (1995), contendo inclusive alguns itens idênticos aos empregados pela referida autora em sua pesquisa.

Ao todo foram apresentados 12 itens para correção das violações sintáticas (dois itens de treinamento e 10 itens de exame). A criança recebia um ponto por resposta correta, podendo o escore de acertos variar de zero a 10.

O objetivo dessa tarefa era verificar a capacidade dos sujeitos de focar sua atenção nas relações estruturais das sentenças, analisando as alterações na ordem das palavras que as compõem (mudanças na ordem sujeito/substantivo/adjetivo, ou inversões entre artigos/substantivos/adjetivos no interior dessas estruturas sintáticas).

\section{C) Tarefa de correção das violações gramaticais contidas nas frases}

Nesta tarefa, as crianças deviam corrigir uma série de 12 frases gramaticalmente incorretas, sendo duas de treinamento e 10 de exame. Em cada uma das frases, apenas uma palavra estava incorreta, e envolviam anomalias morfêmicas como, por exemplo, "Marta veste sua casaco", "Juliana tem lindas olhos", "Cláudio viu dois cavalo". O escore de acertos das crianças podia variar de zero a 10 , sendo um ponto por palavra que ela corrigisse.

Destaca-se que esta tarefa é semelhante a outras que foram utilizadas por Bowey (1986) com crianças falantes do inglês e, mais tarde, por Demont (1994/1997) com crianças falantes do francês.

Esta tarefa também visava avaliar a capacidade dos sujeitos de focar sua atenção nas relações estruturais das sentenças, com a diferença de que, nesta tarefa, eles deviam analisar a mudança de morfemas (p. ex.: variações
Tabela 1. Média e desvio padrão dos escores obtidos na tarefa de memória verbal e no teste das Matrizes Progressivas.

\begin{tabular}{lcccccc}
\hline \multirow{2}{*}{ Grupo } & $\mathbf{N}$ & \multirow{2}{*}{$\begin{array}{c}\text { Idade } \\
\text { (média) }\end{array}$} & \multicolumn{2}{c}{$\begin{array}{c}\text { Memória verbal } \\
\text { (12 sentenças) }\end{array}$} & \multicolumn{2}{c}{$\begin{array}{c}\text { Raven } \\
\text { (escores Z) }\end{array}$} \\
\cline { 4 - 7 } & & & M. & D.P. & M. & D.P. \\
\hline 1 & 20 & 11 a. $6 \mathrm{~m}$. & 9,00 & 1,12 & 0,52 & 0,40 \\
2 & 20 & 7a. $1 \mathrm{~m}$. & 8,10 & 1,17 & 0,63 & 0,52 \\
3 & 20 & 11a. $5 \mathrm{~m}$. & 9,00 & 1,34 & 0,54 & 0,40 \\
\hline Total & 60 & 10a. & 8,70 & 1,27 & 0,56 & 0,44 \\
\hline
\end{tabular}

na concordância verbal com relação ao tempo ou à pessoa, variações na concordância dos pronomes possessivos, flexões indevidas de substantivos e adjetivos relativas ao gênero ou número, etc.)

\section{Resultados}

\section{Medidas de controle}

A tabela 1 mostra a média com o respectivo desvio padrão dos escores obtidos na tarefa de memória verbal, bem como a média e o desvio padrão dos escores $\mathrm{Z}$ no teste das Matrizes Progressivas de Raven.

Os resultados obtidos mostram que os escores em memória verbal estão mais relacionados com a idade do que com o nível de leitura e de escrita.

A comparação das médias utilizando a ANOVA (one-way) mostrou que a diferença entre os grupos é significativa $[\mathrm{F}(2,57)$ $=3,67 ; p=0,03]$. Entretanto, a comparação dos grupos um a um, usando-se o teste post hoc de Scheffé, mostrou que não existe nenhum par em que os grupos sejam significativamente diferentes. Assim, como o grupo 1 obteve um escore ligeiramente superior ao do grupo 2, qualquer diferença de desempenho nas outras tarefas, em favor do grupo 2, não pode se atribuída à memória verbal.

Em relação ao teste das Matrizes Progressivas, os resultados mostram que o grupo 2 tem uma média ligeiramente superior aos outros dois grupos. No entanto, a comparação das médias utilizando-se a ANOVA (one-way) mostrou que essa diferença não é significativa $[\mathrm{F}(2,57)=0,36 ; p=0,70]$. Portanto, os resultados mostram que quaisquer diferenças que venham a ser encontradas nas outras tarefas não poderão ser atribuídas às habilidades medidas pelo teste do Raven.

\section{Tarefas de leitura e escrita de palavras reais e de palavras inventadas}

Na tabela 2 são mostrados os escores percentuais obtidos pelos sujeitos de cada um dos três grupos, nas tarefas de leitura e escrita de palavras reais e inventadas.

Para comparar as médias obtidas pelos três grupos na tarefa de leitura foi utilizada a prova não-paramétrica de Kruskal-Wallis, já que não existia homogeneidade nas variâncias dos grupos. Esta prova mostrou que existe uma diferença significativa entre os grupos tanto na leitura das palavras reais $\left(\chi^{2}=34,10, \mathrm{gl}=2 ; p<0,001\right)$ como na leitura das palavras inventadas $\left(\chi^{2}=25,22, \mathrm{gl}=2 ; p<0,001\right)$. A comparação das médias nas palavras reais mostra que a diferença entre os grupos é devida ao melhor desempenho 
Tabela 2. Média dos percentuais de acertos nas tarefas de leitura e de escrita, por grupo.

\begin{tabular}{|c|c|c|c|c|c|c|c|c|c|c|c|c|c|}
\hline \multirow{3}{*}{ Grupo } & \multirow{3}{*}{$\mathbf{N}$} & \multicolumn{6}{|c|}{ Percentual de acertos na leitura } & \multicolumn{6}{|c|}{ Percentual de acertos na escrita } \\
\hline & & \multicolumn{2}{|c|}{$\begin{array}{c}\text { Palavras } \\
\text { reais } \\
\text { (36 palavras) }\end{array}$} & \multicolumn{2}{|c|}{$\begin{array}{c}\text { Palavras } \\
\text { inventadas } \\
\text { (18 palavras) }\end{array}$} & \multicolumn{2}{|c|}{$\begin{array}{c}\text { Total } \\
\text { (54 palavras) }\end{array}$} & \multicolumn{2}{|c|}{$\begin{array}{c}\text { Palavras } \\
\text { reais } \\
\text { (36 palavras) }\end{array}$} & \multicolumn{2}{|c|}{$\begin{array}{c}\text { Palavras } \\
\text { inventadas } \\
\text { (18 palavras) }\end{array}$} & \multicolumn{2}{|c|}{$\begin{array}{c}\text { Total } \\
\text { (54 palavras) }\end{array}$} \\
\hline & & M. & D.P. & M. & D.P. & M. & D.P. & M. & D.P. & M. & D.P. & M. & D.P. \\
\hline 1 & 20 & 79,44 & 13,20 & 53,89 & 14,87 & 70,93 & 12,46 & 51,81 & 11,55 & 53,89 & 11,83 & 52,41 & 9,97 \\
\hline 2 & 20 & 79,44 & 14,43 & 67,22 & 20,78 & 75,37 & 15,52 & 56,25 & 14,13 & 67,50 & 12,91 & 60,00 & 12,78 \\
\hline 3 & 20 & 97,64 & 2,26 & 85,28 & 8,88 & 93,52 & 3,43 & 85,83 & 7,69 & 80,00 & 10,10 & 83,89 & 7,36 \\
\hline Total & 60 & 85,51 & 14,13 & 68,80 & 20,10 & 79,94 & 15,11 & 64,63 & 18,93 & 67,13 & 15,72 & 65,43 & 16,88 \\
\hline
\end{tabular}

do grupo 3. Em relação às palavras inventadas, como as médias dos três grupos são diferentes, foi realizada a prova de Kolmogorov-Smirnov para comparar o grupo 1 com o grupo 2 e o grupo 2 com o grupo 3. Esta prova mostrou que apenas é significativa a diferença entre as médias dos grupos 2 e $3(p=0,005)$.

Na prova de escrita das palavras reais, a comparação das médias obtidas pelos três grupos foi realizada utilizando a prova não-paramétrica de Kruskal-Wallis, porque não existia homogeneidade nas variâncias dos grupos. Esta prova mostrou a existência de uma diferença significativa entre os grupos $\left(\chi^{2}=37,84, \mathrm{gl}=2 ; p<0,001\right)$. A comparação das médias indica que essa diferença se deve, provavelmente, ao melhor desempenho do grupo 3 em relação aos outros dois grupos. Já para comparar as médias obtidas pelos três grupos na escrita de palavras inventadas foi efetuada uma ANOVA (one-way), pois nesta tarefa as distribuições eram normais e as variâncias homogêneas. Os resultados desta prova mostraram a existência de uma diferença significativa entre os grupos $[\mathrm{F}(2,57)=25,04 ; \mathrm{p}<0,001]$. O teste post hoc de Scheffé mostrou que os três grupos apresentam diferenças significativas entre si.

\section{Tarefas de avaliação da consciência fonológica}

A tabela 3 sumariza os resultados obtidos nas tarefas de consciência fonológica.

Esses resultados indicam que em todas as tarefas o desempenho do grupo 1 foi menor do que o desempenho dos outros grupos.

$\mathrm{Na}$ tarefa de segmentação fonológica, foi utilizada a prova não-paramétrica de Kruskal-Wallis para verificar a diferença entre os grupos. Esta prova confirmou que as diferenças entre os grupos são significativas $\left(\chi^{2}=26,53, \mathrm{gl}=2 ; p<0,001\right)$. Essa diferença se deve, provavelmente, ao fraco desempenho do grupo 1 em relação aos outros dois grupos.
Além disso, foi efetuada uma análise das segmentações fonológicas realizadas pelos três grupos de sujeitos. Assim, no que se refere aos tipos de segmentação fonológica efetuados para as palavras monossílabas, verifica-se que a maioria dos problemas na segmentação fonêmica envolveu a palavra "flor"; em todos os grupos, o número de segmentações não-fonêmicas apresentadas para esta palavra é superior à soma das segmentações não-fonêmicas apresentadas para as outras palavras ("giz", "sol", "boi"). Donde se conclui que a complexidade da palavra monossilábica "flor" (CCVC) dificultou a sua segmentação fonêmica.

A análise das segmentações relativas às palavras dissílabas indica que nenhum sujeito apresentou dificuldade em segmentar fonemicamente a palavra "sapo" (padrão silábico $\mathrm{CV} / \mathrm{CV}$ ). No presente estudo, as dificuldades em efetuar segmentações fonêmicas nas palavras dissílabas recaíram naquelas que possuíam sílabas complexas (CV/CCV: cobra, carro; $\mathrm{CCV} / \mathrm{CV}$ : prato; $\mathrm{CVV} / \mathrm{CV}$ : peixe; $\mathrm{CVC} / \mathrm{CV}$ : barco). Neste sentido, verificou-se que o tipo de segmentação mais freqüente nos grupos 1 ( 20 casos) e 2 ( 7 casos) foi transformar sílabas não $\mathrm{CV}$ em sílabas $\mathrm{CV}$ pela omissão de um fonema (p. ex.: b-a-c-o, c-o-b-a, p-e-X-e). Além desse tipo de segmentação, identificou-se nos três grupos ( 7 casos no grupo 1, 1 caso no grupo 2 e 2 casos no grupo 3) a não separação fonêmica do "ataque" nas sílabas CCV (p. ex.: pr-a-t-o, co-br-a). Finalmente, verificou-se, apenas nos grupos 1 (4 casos) e 2 (2 casos), a ocorrência de um tipo de segmentação que envolve a inversão de alguns fonemas (p. ex.: b-r-a-c-o, p-a-r-t-o, c-o-b-a-r, p-e-x-i-e).

No que se refere à tarefa de categorização fonológica, foi utilizada a prova não-paramétrica de Kruskal-Wallis para comparar o desempenho dos três grupos. Esta prova mostrou a existência de diferenças significativas entre os grupos $\left(\chi^{2}=\right.$ $29,92, \mathrm{gl}=2 ; p<0,001)$. Comparando as médias verifica-se que essa diferença é devida provavelmente ao desempenho mais fraco do grupo 1 em relação aos outros dois grupos.

Tabela 3 - Média dos percentuais de acertos nas três tarefas de consciência fonológica e escore único de consciência fonológica.

\begin{tabular}{|c|c|c|c|c|c|c|}
\hline \multirow[t]{2}{*}{ Grupo } & \multirow[t]{2}{*}{$\mathbf{N}$} & \multicolumn{3}{|c|}{$\begin{array}{l}\text { Médias percentuais das tarefas de } \\
\text { consciência fonológica }\end{array}$} & \multicolumn{2}{|c|}{$\begin{array}{l}\text { Escore de } \\
\text { consciência } \\
\text { fonológica }\end{array}$} \\
\hline & & $\begin{array}{l}\text { Segmentação } \\
\text { fonológica }\end{array}$ & $\begin{array}{l}\text { Categorização } \\
\text { Fonológica }\end{array}$ & $\begin{array}{l}\text { Subtração de } \\
\text { fonema inicial }\end{array}$ & M. & D.P. \\
\hline 1 & 20 & 62,50 & 78,33 & 86,00 & 75,61 & 8,66 \\
\hline 2 & 20 & 82,50 & 92,50 & 96,00 & 90,33 & 6,51 \\
\hline 3 & 20 & 90,00 & 96,67 & 98,50 & 95,06 & 3,21 \\
\hline Total & 60 & 78,33 & 89,17 & 93,50 & 87,00 & 10,53 \\
\hline
\end{tabular}


Tabela 4 - Média dos percentuais de acertos nas três tarefas de consciência sintática e escore único de consciência sintática.

\begin{tabular}{lcccccc}
\hline \multirow{2}{*}{ Grupo } & N & \multicolumn{3}{c}{$\begin{array}{c}\text { Médias percentuais das tarefas de } \\
\text { consciência sintática }\end{array}$} & \multicolumn{2}{c}{$\begin{array}{c}\text { Escore de } \\
\text { consciência } \\
\text { sintática }\end{array}$} \\
\cline { 3 - 7 } & & Complementação & $\begin{array}{c}\text { Ordem dos } \\
\text { Componentes }\end{array}$ & $\begin{array}{c}\text { Violações } \\
\text { gramaticais }\end{array}$ & M. & D.P. \\
\hline 1 & 20 & 76,67 & 83,00 & 73,00 & 77,56 & 7,11 \\
2 & 20 & 72,67 & 86,50 & 79,50 & 79,56 & 7,24 \\
3 & 20 & 90,33 & 97,00 & 83,50 & 90,28 & 3,62 \\
\hline Total & 60 & 79,89 & 88,83 & 78,67 & 82,46 & 8,31 \\
\hline
\end{tabular}

Na tarefa de subtração de fonema inicial também foi utilizado o teste de Kruskal-Wallis para comparar o desempenho dos três grupos. Este teste mostrou que a diferença entre os grupos é significativa $\left(\chi^{2}=19,98, \mathrm{gl}=2 ; p<0,001\right)$, provavelmente devido ao pior desempenho do grupo 1 .

Portanto, considerando os resultados das três tarefas de avaliação da consciência fonológica, verifica-se que todas elas discriminam o grupo 1 dos outros dois grupos. Assim, definiu-se um escore único de consciência fonológica, a partir da média dos escores percentuais obtidos nas três tarefas (segmentação fonológica, categorização fonológica, subtração de fonema inicial), como mostra a tabela 3.

\section{Tarefas de avaliação da consciência sintática}

A tabela 4 sumariza os resultados obtidos nas três tarefas de consciência sintática (complementação de palavras omitidas do texto, correção da ordem dos componentes das frases e correção das violações gramaticais contidas nas frases).

No que concerne aos resultados da tarefa de complementação, a ANOVA (one-way) confirmou que as diferenças entre os grupos são significativas [F $(2,57)=16,96 ; p<0,001]$ e se devem ao melhor desempenho do grupo 3 em relação aos outros dois grupos (verificado pelo teste post hoc de Scheffé).

Por outro lado, o exame dos resultados apresentados pelos três grupos na tarefa de correção da ordem dos componentes das frases aponta que, diferentemente dos resultados na tarefa de complementação, os sujeitos do grupo 1 foram os que apresentaram pior desempenho; embora a diferença entre o desempenho dos grupos 1 e 2 tenha sido muito pequena. Como as variâncias não eram homogêneas, foi utilizado o teste de Kruskal-Wallis para comparar o desempenho dos grupos. Este teste confirmou que a diferença entre eles é significativa e se deve, provavelmente, ao melhor desempenho do grupo 3 em relação aos outros dois grupos $\left(\chi^{2}=19,23\right.$, $\mathrm{gl}=2 ; p<0,001)$.

$\mathrm{Na}$ tarefa de correção das violações gramaticais, os sujeitos do grupo 1 também tiveram um desempenho inferior ao desempenho dos sujeitos do grupo 2 e estes tiveram um desempenho pior que os sujeitos do grupo 3. A ANOVA (one-way) confirmou que as diferenças entre os grupos são significativas $[\mathrm{F}(2,57)=8,06 ; p<0,001]$. O teste post hoc de Scheffé mostrou que é significativa apenas a diferença de desempenho entre o grupo 1 e o grupo 3, não existindo diferença significativa entre os grupos 1 e 2 , nem entre os grupos 2 e 3.

Sumariando os resultados obtidos nas três tarefas de avaliação da consciência sintática, verifica-se que todas elas mostram um desempenho melhor do grupo 3 quando comparado aos outros dois grupos e que o desempenho dos sujeitos com o mesmo nível de leitura e de escrita (grupos 1 e 2) são muito semelhantes. Assim, definiu-se um escore único de consciência sintática a partir da média dos escores percentuais obtidos nas três tarefas, como mostra a tabela 4 .

\section{Discussão}

Sintetizando vários elementos apresentados na introdução, pode-se dizer que a consciência fonológica e a aprendizagem da leitura e da escrita desenvolvem-se em interação: a consciência fonológica contribui para o sucesso da aprendizagem da leitura e da escrita, do mesmo modo que a aprendizagem da leitura alfabética contribui para o desenvolvimento da consciência fonêmica.

Entretanto, formulou-se a hipótese de que, mesmo após ter cursado algumas séries do ensino fundamental, o desempenho dos alunos em leitura e em escrita está relacionado a níveis diferentes de consciência fonológica. Assim, para avaliar a consciência fonológica dos sujeitos desta pesquisa foram utilizadas três tarefas: segmentação fonológica, categorização fonológica e subtração de fonema inicial.

Em relação à tarefa de segmentação fonológica, os resultados demonstraram que todos os sujeitos tiveram maior dificuldade na segmentação fonêmica das palavras dissílabas do que na das palavras monossílabas, embora essa dificuldade tenha sido mais acentuada nos sujeitos do grupo 1 . Destaca-se, ainda, que as dificuldades de segmentação fonêmica das palavras dissílabas não envolveram as palavras de padrão silábico $\mathrm{CV} / \mathrm{CV}$, mas sim aquelas que possuem sílabas complexas (padrões silábicos $\mathrm{CV} / \mathrm{CCV}, \mathrm{CCV} / \mathrm{CV}$, $\mathrm{CVV} / \mathrm{CV}$ e $\mathrm{CVC} / \mathrm{CV})$.

No que se refere à tarefa de categorização fonológica, os resultados não foram menos interessantes. Na realidade, eles estão de acordo com as conclusões de estudos anteriores (Cardoso-Martins, 1995; Demont, 1994/1997; Liberman, Shankweiller, Fischer \& Carter, 1974), pois revelaram que a identificação e a manipulação de sílabas são realizadas mais facilmente do que a identificação e a manipulação de fonemas.

É pertinente recordar a relação registrada por CardosoMartins (1995) de que a capacidade de identificação da sílaba inicial foi preditiva da leitura, apesar de não ter servido para prever a capacidade ortográfica. Além disso, a mesma pesquisadora verificou uma relação preditiva entre capacidade de identificação de aliteração e posterior sucesso na aprendizagem da leitura e da escrita. Nesta perspectiva, e com base nos resultados do presente estudo, sugere-se que as dificul- 
dades em leitura e em escrita dos sujeitos do grupo 1 podem ser atribuídas, entre outras, às dificuldades na detecção de identidades fonêmicas (inicial e final). Portanto, confirma-se que a consciência fonêmica é fundamental na aquisição e no aperfeiçoamento da leitura e da escrita em Português.

Os resultados obtidos na tarefa de subtração de fonema inicial mostram que, de modo geral, o desempenho nesta tarefa foi bom, embora os sujeitos do grupo 1 tenham apresentado o pior desempenho. Na realidade, os sujeitos do grupo 1 apresentaram um escore médio de $86 \%$, o que é consideravelmente inferior ao desempenho do grupo $2(96 \%)$ e do grupo $3(98,5 \%)$.

Deste modo, embora os resultados do estudo de Morais, Cary, Alegria e Bertelson (1979) apontem que a capacidade de manipular fonemas é estimulada pela aprendizagem da leitura, alguns sujeitos do presente estudo (grupo 1), que possuem entre três e quatro anos de escolaridade, permanecem com dificuldades na manipulação de fonemas.

Em suma, os resultados obtidos nas tarefas de avaliação da consciência fonológica são unânimes em apontar a defasagem dessa consciência nos sujeitos com dificuldades na leitura e na escrita; defasagem essa que envolve principalmente a identificação e a manipulação de fonemas.

Por outro lado, conforme já foi destacado, existe também considerável suporte teórico e empírico sustentando a hipótese de que os bons leitores/escritores utilizam, além dos aspectos fonológicos, aspectos sintáticos como estratégia de leitura e de escrita.

Assim, para avaliar a consciência sintática dos sujeitos desta pesquisa foram utilizadas três tarefas: complementação de palavras omitidas do texto, correção da ordem dos componentes das frases e correção das violações gramaticais contidas nas frases. O conjunto dos resultados obtidos nessas tarefas demonstra que os escores dos grupos 1 e 2 são muito semelhantes e que o grupo 3 apresentou um desempenho superior ao dos outros dois grupos. Ou seja, embora os sujeitos do grupo 1 tenham apresentado um desempenho nas tarefas de consciência sintática adequado ao seu nível de leitura e escrita, esse desempenho é bastante inferior ao dos sujeitos do grupo 3 (grupo controle por idade). Entretanto, é importante destacar que durante o estudo verificou-se que algumas das frases da tarefa de correção das violações gramaticais podem parecer corretas para as crianças falantes dos dialetos orais mais afastados da norma culta/padrão; portanto, o desempenho inferior dos sujeitos do grupo 1 pode não estar relacionado a uma ausência ou deficiência na reflexão metalingüística. Na realidade, este foi um problema detectado em relação à utilização dessa tarefa, cujo resultado pode estar relacionado prioritariamente com o fato de que as crianças do grupo 1 convivem com normas diferentes.

De qualquer forma, a análise dos escores dos três grupos nas tarefas de consciência sintática sugere que as habilidades medidas nessas tarefas são aperfeiçoadas com as experiências em leitura e em escrita, provavelmente porque a linguagem escrita, se comparada com a linguagem oral, oferece maiores possibilidades de análise e reflexão a respeito das estruturas sintáticas.

Contudo, considerando-se os resultados obtidos na avaliação de ambas as habilidades (consciência fonológica e consciência sintática), infere-se que os problemas de consci- ência fonológica dos sujeitos do grupo 1 não lhes permitiram beneficiar-se das atividades de leitura e de escrita (como aconteceu com os sujeitos do grupo 3), impedindo, assim, o desenvolvimento da consciência sintática. Dessa forma, os sujeitos do grupo 1, embora com mais tempo de escolaridade, permanecem com o mesmo nível de consciência sintática que os sujeitos do grupo 2, que são mais inexperientes.

Sintetizando os resultados obtidos, pode-se afirmar que se confirmou a hipótese de que os sujeitos que apresentam os escores mais elevados nas tarefas que avaliam as habilidades metalingüísticas (consciência fonológica e consciência sintática) mostram também os melhores desempenhos nas tarefas de leitura e de escrita. A análise de correlação de Pearson mostrou que o desempenho na tarefa de leitura se correlaciona positiva e significativamente tanto com o escore de consciência fonológica $(\mathrm{r}=0,61 ; p<0,01)$ como com o escore de consciência sintática $(\mathrm{r}=0,68 ; p<0,01)$. Além disso, o teste de correlação de Pearson mostra que o desempenho na tarefa de escrita também se correlaciona positiva e significativamente, tanto com o escore de consciência fonológica $(\mathrm{r}=$ $0,63 ; p<0,01)$, como com o escore de consciência sintática $(\mathrm{r}=0,66 ; p<0,01)$.

Uma outra hipótese do presente estudo era que o grupo de sujeitos com dificuldades de aprendizagem da leitura e da escrita apresentaria escores inferiores nas tarefas que avaliam a consciência fonológica e a consciência sintática, quando comparados com os demais sujeitos da pesquisa, tanto com aqueles de sua idade cronológica, como com aqueles de seu nível de leitura e escrita. Essa hipótese foi confirmada apenas para os escores em consciência fonológica. Em relação à consciência sintática, não foi observada diferença significativa entre os grupos 1 e 2, os quais tiveram um desempenho inferior ao do grupo 3.

Conclui-se, portanto, que a explicação das dificuldades em leitura e escrita a partir das habilidades metalingüísticas aqui examinadas é um tema complexo, que merece novos estudos, sobretudo estudos longitudinais. Esse tipo de investigação poderá esclarecer melhor como e quando são desenvolvidas essas habilidades metalingüísticas e, mais do que isso, poderá revelar quão flexível é a seqüência de utilização dos aspectos fonológicos e sintáticos como estratégias de leitura e de escrita.

Contudo, acredita-se que os resultados do presente estudo já apresentam importantes implicações educacionais, possibilitando um aprimoramento na montagem dos programas de intervenção destinados aos alunos com dificuldades em leitura e em escrita.

$\mathrm{Na}$ realidade, os resultados obtidos corroboram os de outras pesquisas, mostrando que grande parte das dificuldades em leitura e escrita dos sujeitos do grupo 1 está relacionada com problemas de natureza fonológica. Além disso, eles confirmam a afirmação de Torgesen, Wagner e Rashotte (1994) de que, na ausência de intervenções específicas, as diferenças entre as crianças nas tarefas de consciência fonológica tendem a permanecer, especialmente aquelas diferenças relativas à consciência fonêmica.

Neste sentido, sugere-se que os sujeitos com dificuldades de aprendizagem da leitura e da escrita precisam participar de atividades que possam promover o desenvolvimento da consciência fonológica, a qual envolve não apenas a habili- 
dade mecânica de percepção dos fonemas, mas a habilidade intencional (meta-cognitiva) de manipulá-los. Por exemplo, os professores podem implementar atividades em que num determinado contexto seja trocado um som por outro, efetuando os "testes de comutação" (Cagliari, 1997). Paralelamente, deve-se promover a participação desses alunos em atividades que levem ao reconhecimento e à discriminação dos padrões de correspondência entre ortografia e fonologia, capacitando-os a associarem sequiências de letras com seus sons. Desse modo, o sujeito poderá utilizar simultaneamente diferentes estratégias, incluindo a leitura e/ou escrita de palavras em "pedaços", o que propicia maior eficiência, uma vez que se desfaz a necessidade de ficar associando letras e sons individualmente.

Enfim, sugere-se que a intervenção pedagógica indicada às crianças com dificuldades de leitura e de escrita deve implementar atividades que promovam a reflexão sobre a linguagem escrita, em particular a reflexão acerca do aspecto fonológico (metafonologia).

\section{Referências}

Alégria, J., Leybaert, J. \& Mousty, P. (1997). Aquisição da leitura e distúrbios associados: avaliação, tratamento e teoria. Em J. Grégoire \& B. Piérart, Avaliação dos problemas de leitura: os novos modelos teóricos e suas implicações diagnósticas (pp. 105-124). (M.R.B. Osório, Trad.). Porto Alegre: Artes Médicas. (Trabalho original publicado em 1994).

Barrera, S.D. (2000). Linguagem oral e alfabetização: um estudo sobre variação lingüística e consciência metalingüística em crianças da $1^{a}$ série do ensino fundamental. Tese de doutorado, Instituto de Psicologia, Universidade de São Paulo, São Paulo.

Bertelson, P., Morais, J., Alegria, J. \& Content, A. (1985). Phonetic analysis capacity and learning to read. Nature, 313 (3), 73-74.

Bowey, J.A. (1986). Syntactic awareness in relation to reading skill and ongoing reading comprehension monitoring. Journal of Experimental Child Psychology, 41, 282-299.

Bradley, L. \& Bryant, P.E. (1983). Categorizing sounds and learning to read - a causal connection. Nature, 301, 419-421.

Bradley, L. \& Bryant, P.E. (1978). Difficulties in auditory organization as a possible cause of reading backwardness. Nature, 271, 746-747.

Bryant, P.E. \& Bradley, L. (1987). Problemas de aprendizagem de leitura. (I.C.S. Ortiz, Trad.) Porto Alegre: Artes Médicas. (Trabalho original publicado em 1985).

Bryant, P.E. \& Goswami, U. (1987). Beyond grapheme-phoneme correspondence. Cahiers de Psychologie Cognitive, 7, 439443.

Bryant, P.; Nunes, T. \& Binddman, M. (1997). Backward readers' awareness of language: Strengths and weaknesses. European Journal of Psychology of Education, 12 (4), 357-372.

Byrne, B. (1996). Treinamento da consciência fonêmica em crianças pré-escolares: por que fazê-lo e qual o seu efeito? Em C. Cardoso-Martins (Org.), Consciência fonológica \& alfabetização (pp. 37-67). Petrópolis: Vozes.

Byrne, B. \& Fielding-Barnsley, R. (1989). Phonemic awareness and letter knowledge in the child's acquisition of the alphabetic principle. Journal of Educational Psychology, 81 (3), 313-321.
Byrne, B. \& Fielding-Barnsley, R. (1993). Evaluation of a program to teach phonemic awareness to young children: a 1-year followup. Journal of Educational Psychology, 85 (1), 104-111.

Cagliari, L.C. (1997). Alfabetização \& lingüística. São Paulo: Scipione.

Capovilla, A.G.S. (1999). Leitura, escrita e consciência fonológica: desenvolvimento intercorrelações e intervenções. Tese de Doutorado, Instituto de Psicologia, Universidade de São Paulo, São Paulo.

Cardoso - Martins, C. (1995). Sensitivity to rhymes, syllables, and phonemes in literacy acquisition in Portuguese. Reading Research Quarterly, 30 (4), 808-827.

Carraher, T.N. \& Rego, L.L.B. (1981). O realismo nominal como obstáculo na aprendizagem da leitura. Cadernos de Pesquisa,39, 3-10.

Cordeiro, M.H.B.V. (1999). Towards the understanding of the alphabetic principle. Doctoral Thesis, Institute of Education, University of London, London.

Curitiba. (1992). Prefeitura Municipal de Curitiba. Secretaria Municipal de Educação. Proposta de Educação Especial na Secretaria Municipal de Educação. Curitiba.

Demont, E. (1997). Consciência fonológica, consciência sintática: que papel (ou papéis) desempenha na aprendizagem eficaz da leitura? Em J. Grégoire \& B. Piérart, Avaliação dos problemas de leitura: os novos modelos teóricos e suas implicações diagnósticas (pp. 189-201). (M.R.B. Osório, Trad.). Porto Alegre: Artes Médicas. (Trabalho original publicado em 1994).

Ehri, L.C. \& Robbins, C. (1992). Beginners need some decoding skill to read words by analogy. Reading Research Quarterly, 27, 13-26.

Goswami, U \& Bryant, P. (1997). Phonological skills and learning to read. Hove, UK: Psychology Press Ltd.

Gottardo, A., Stanovich, K.E. \& Siegel, L.S. (1996). The relationships between phonological sensitivity, syntactic processing, and verbal working memory in the reading performance of third-grade children. Journal of Experimental Child Psychology, 63, 563-582.

Guthrie, J.T. (1973). Reading comprehension and syntactic responses in good and poor readers. Journal of Educational Psychology, 65 (3), 294-299.

Hohn, W. \& Ehri, L. (1983). Do alphabet letrrers help prereaders acquire phonemic segmentation skill? Journal of Educational Psychology, 75 (5), 752-762.

Juel, C., Griffith, P.L. \& Gough, P.B. (1986). Acquisition of literacy: A longitudinal study of children in first and second grade. Journal of Educational Psychology, 78 (4), 243-255.

Kajihara, O.T. Avaliação das habilidades fonológicas de disléxicos do desenvolvimento. Tese de doutorado, Instituto de Psicologia, Universidade de São Paulo, São Paulo.

Liberman, I.Y., Shankweiller, D., Fischer, F.W. \& Carter, B. (1974). Explicit syllable and phoneme segmentation in the young child. Journal of Experimental Child Psychology, 18, 201-212.

Lundberg, I., Frost, J. \& Petersen, O. (1988). Effects of an extensive program for stimulating phonological awareness in preschool children. Reading Research Quarterly, 23 (3), 263-284.

Maluf, M.R. \& Barrera, S.D. (1997). Consciência fonológica e linguagem escrita em pré-escolares. Psicologia: Reflexão $e$ Crítica, 10 (1), 125-145.

Morais, A.M.P. (1997). A relação entre a consciência fonológica e as dificuldades de leitura. São Paulo: Vetor. 


\section{S. R. K. Guimarães}

Morais, J., Cary, L., Alegria, J. \& Bertelson, P. (1979). Does awareness of speech as a sequence of phones arise spontaneously? Cognition, 7, 323- 331.

Perfetti, C.A., Beck, I., Bell, L.C. \& Hughes, C. (1987). Phonemic knowledge and learning to read are reciprocal: a longitudinal study os first grande children. Merrill-Palmer Quarterly, 33 (3), 283-319.

Pinheiro, A. M. V. (1994). Leitura e escrita: uma abordagem cognitiva. Campinas: Editorial Psy II.

Rego, L.L.B. (1993). O papel da consciência sintática na aquisição da língua escrita. Temas em Psicologia, 1, 79-87.

Rego, L.L.B. (1995). Diferenças individuais na aprendizagem inicial da leitura : Papel desempenhado por fatores metalingüísticos. Psicologia: Teoria e Pesquisa, 11 (1), 51-60.

Shankweiler, D., Crain, S., Brady, S. \& Macaruso, P. (1992). Identifying the causes of reading disability. Em P.B. Gough, L.C. Ehri \& R. Treiman, Reading acquisition ( $p$ p. 275-305). Hillsdale: Erlbaum.

Share, D.L. (1995). Phonological recoding and self-teaching: sine qua non of reading acquisition. Cognition, 55, 151-218.

Stanovich, K.E., Cunningham, A.E. \& Cramer, B.B. (1984). Assessing phonological awareness in kindergarten children: issues of task comparability. Journal of Experimental Child Psychology, 38, 175-190.

Stein, L.M. (1994). TDE: teste de desempenho escolar: manual para aplicação e interpretação. São Paulo: Casa do Psicólogo.
Torgesen, J.K.; Wagner, R.K.; Rashtte, C.A. (1994). Longitudinal of phonological processing and reading. Journal of Learning Disabilities, 27 (5), 276-286.

Treiman, R. \& Baron, J. (1983). Phonemic-analysis training helps children benefit from spelling-sound rules. Memory \& Cognition, 11 (4), 382-389.

Tunmer, W.E. (1990). The role of language prediction skills in beginning reading. New Zealand Journal of Educational Studies, 25 (2), 95-114.

Tunmer, W.E., Herriman, M.L. \& Nesdale, A.R. (1988). Metalinguistic abilities and beginning reading. Reading Research Quarterly, 23, 134-158.

Tunmer, W.E., Nesdale, A.R. \& Wright, A.D. (1987). Syntactic awareness and reading acquisition. British Journal of Developmental Psychology, 5, 25-34.

Vernon, S.A. (1998). Types of segmentation in orality and writing in Spanish-speaking children. Querétaro, México, Universidad Autónoma de Querétaro. 43p. [Digitado].

Williams, J. (1980). Teaching decoding with an emphasis on phoneme analysis and phoneme blending. Journal of Educational Psychology, 72 (1), 1-15.

Yopp, H.K. (1988). The validity and reliability of phonemic awareness tests. Reading Research Quarterly, 23 (2), 159-177. 


\section{Anexo A}

Frase de treinamento e texto da história utilizados na tarefa de complementação.

Treino: Certa vez eu sonhei que embaixo da "uhm" havia um "uhm" medonho.

\section{Os dois ratinhos}

Era uma vez dois ratinhos. Eles moravam numa "uhm" de fazenda, que era uma maravilha de moradia, pois havia muitos lugares interessantes no forro e no porão.

Uma noite, os dois ratinhos saíram para um passeio na cozinha. Eles encontraram um saco de fubá num canto, muitas lingüiças penduradas "uhm" despensa e "uhm" queijos na prateleira.

Tinha tanta coisa para "uhm" que nem dá para lembrar tudo.

Os dois ratinhos comeram até se empanturrarem. Depois, deu sede. Então, eles viram uma tigela de leite, que a cozinheira deixara para fazer coalhada.

Assim, para matar "uhm" sede e a gulodice ao mesmo "uhm", eles se equilibraram na borda da tigela "uhm" beber. Entretanto, um deles perdeu o equilíbrio e plaft! Caiu lá dentro. Na queda, tentou se agarrar ao rabo do "uhm" e plaft! O segundo ratinho também "uhm".

Começaram a tentar sair. Mas era "uhm", a borda da tigela escorregava. E "uhm" estavam pesados, de barriga "uhm".

Foram nadando, se batendo e ficando cansados. Um deles simplesmente desistiu. O outro resolveu que não ia entregar os pontos. Nadava, nadava, mesmo que fosse em círculos, só para não parar de lutar. Passou assim a noite toda.

No "uhm" seguinte, quando a cozinheira chegou na "uhm", teve duas surpresas. Dentro da tigela de coalhada tinha um ratinho morto. Mas a surpresa maior não foi essa. Foi ver que a coalhada tinha virado manteiga, de tanto "uhm" batida. E por cima havia, muito nítido, um caminho feito de rastros, eram as pegadas de um ratinho que saíra caminhando sobre a manteiga e fora embora. 